\title{
CONTINUITY, IDENTITY AND FOLK STUDIES IN GREECE
}

\author{
Evangelos Gr. Avdikos
}

\begin{abstract}
This article will focus on folk studies in Greece and the role they played both in the creation of the Greek national state and in the shaping of Greek identity. The Great Idea, the official ideology of the Greek state from 1843 to 1922 , exercised influence both on the formation and the development of folklore studies. This specific idea of expanding the boundaries of Greece by way of liberating other areas inhabited by Greeks, located outside the Greek national borders of the time, outlined the framework for the folklore studies and defined their relationship with the ancient Greeks and their culture. Thus, the key concept in dealing with the Great Idea is the theory of continuity which is common ground in folk studies around the world. The article is an effort to illuminate folklore studies and Greek folklorists' attitude against basic concepts such as national state, identity, continuity.
\end{abstract}

Key words: continuity, folklore studies, great idea, identity, national state, social anthropology

This article will focus on folk studies in Greece and the role they played both in the creation of the Greek national state and in the shaping of the Greek identity (Herzfeld 1986: 53-73; 1987); the latter was a central prerequisite, especially in the 19th and the early 20 th centuries, for the specification of the political horizons of the Greek state which had moved from theory to practice; in other words, from the Great Idea (Megali Idea) to the expansion of the state boundaries by integrating newly recovered territories such as Epirus, Greek Macedonia, and Thrace which had been up to that time under the occupation of the Ottoman Empire (Skopetea 1988). The Great Idea, the official ideology of the Greek state from 1843 to 1922, was the idea of expanding the boundaries of Greece by liberating other areas outside the Greek national boundaries of the time, which were inhabited by Greeks (Roudometof 2001: 105). This idea was the backbone of the foreign policy of the Greek state up until the Asia Minor catastrophe in 1922, when Greek authorities were forced to give up that dogma which had been wrecked in the water of the Smyrna (Izmir) port (Gianoulopoulos 1999). 
Thus, the key concept in dealing with the Great Idea is the theory of continuity which is common ground in folk studies around the world (Herzfeld 1987: 65-66). The Greek example of the 19th century has to be examined within the context of Romanticism on the one hand (Herzfeld 1987: 1-27; Wilson 1976; Nisbet 1999: 79-82), and on the other, within the necessity for the national identity to be connected with a myth of an ultimate origin (Smith 1986: 149; Shafer 1972: 18-19).

\section{THE THEORY OF CONTINUITY AND FALLMERAYER}

However, if a researcher wants to study the Greek example he or she should take into account the fact that the Greek population belonged to the Ottoman Empire until 1830 (London Protocol, Papageorgiou 2004: 260-261) and that the Ottoman authorities recognized the first independent Greek national state in 1832 (Istanbul Treaty: 284). What should also be taken into account is that the first half of the 19th century generated the national awakening of all the Balkan peoples, being the starting point for friction, conflict and wars over disputed territories (Todorova 1997: 118; Mazower 2002: 95-106).

However, one can realize more clearly the relationship between folk studies and the theory of continuity in Greece when examining Fallmerayer's argument concerning the origin of the population's dwelling in the territories of the newly founded Greek state. Fallmerayer, an Austrian historian, wrote a book, published in 1830, entitled "About the origins of contemporary Greeks" (Fallmerayer 1830). His basic argument throughout the book was that contemporary Greeks had no blood kinship with the ancient Greeks (Jusdanis 2001: 36-38). As is well known, however, in the 19th century the claim for a Greek national state was indeed substantiated by that kinship, i.e. by the bonds between contemporary Greeks and their ancient ancestors.

The starting point of folk culture studies in Greece can be identified with the Greek Enlightenment of the 18th century (Kyriakidou-Nestoros 1978: 1516). The intellectuals of the Greek Enlightenment combined the idea of educating the Greek population with the demand for an independent national state. However, systematic research of Greek folk culture began immediately after the publication of Fallmerayer's book. It should be mentioned at this point that poets, archaeologists and other intellectuals, living in Athens during the second half of 19th century, looked down on contemporary Greek culture as well as on that of Byzantine, recognizing the ancient Greek culture as the only original one. One of them went as far as to argue that only Acropolis was part 
of the Greek state and that everything else was alien, turning, in that way, his back on modern Greece (Dimaras 1985: 339). Such a prevailing attitude affected the priorities of the contemporary Greek state and, as could be expected, had repercussions on the strategic policy concerning the Great Idea.

\section{NIKOLAOS POLITIS: THE FOUNDER}

The debate over Greekness /identity of the Greeks was greatly influenced by Nikolaos Politis (Herzfeld 1986: 97-122), the founder of Greek folk studies, who returned home from his studies in Germany in the 1870's. Politis was the one who later on, in 1909, established Laographia (1909), which was the Greek term both for the Greek Folklore Association and the title of its Journal of Folk Studies (Meraklis 1992).

Folk studies in Greece were called into being in an effort to enhance the arguments in favour of the national state, concerning its survival and the implementation of the Great Idea (Shannan Peckham 2004: 51-53). Fallmerayer's book haunted Greek science and jeopardized the main argument of the Greeks, that is, their blood kinship with the ancient Greeks, on which they based their demand for an independent Greek state.

Thus, Greek scholars devoted all their energy to subverting Fallmerayer's argument by bearing witness to their kinship with ancient Greek culture. History, archaeology and philology joined forces to prove how wrong he was. A scholar named Spyridon Zampelios endeavoured to contest the core of Fallmerayer's main argument by proving the historical continuity of Greece: he formulated a tripartite historical scheme according to which ancient, Byzantine and modern times were the three phases of Greek history (Zampelios 1852). This happened in the second half of the 19th century. Zampelios's scheme exercised a great influence on Greek folk studies. Nikolaos Politis, in particular, used it as an ideological cornerstone. In an article on superstitions, for instance, Politis wrote: "Speaking about superstitions I want to make clear that they originate from the first era of Hellenism" (Kyriakidis 1923: 11). The very use of the term 'Hellenism' was an ideological act, since it implied his belief in the continuity of Greek cultural history. From the moment Politis got involved in folk studies he came into line with Zampelios and Paparigopoulos; the latter was a historian who was the first to write a unified history of the Greek nation from ancient to modern times (Paparigopoulos 1970). Continuity was one of his basic axes in researching folk culture which was indeed the appropriate field in order to track down remains of the first era of Hellenism 
within Modern Greek culture. Thus, his effort was concentrated on collecting material by way of utilizing university students and local teachers in order to compose a cohesive and unified history of Greece. He tried to find the 'historical credit' needed for strengthening the cohesion of the Greek nation, in order to highlight its legalized presence on the international stage (Darko 1917: 68). As a result, Politis sought to focus on the similarities of the present with the ancient past rather than on their differences; the latter would have been extremely dangerous for the homogenizing process in contemporary Greece.

That crucial ideological point determined, to a large extent, Politis's methodological choices which were of two kinds: historical and comparative. Consequently, in his view, continuity was related to the autonomous existence of the present only in as far as that could prove its kinship relations to ancient Greece. Contemporary Greek culture itself did not attract scientific attention; rather, it was the starting point for going back to the ancient Greeks. The comparative aspect of Politis's methodology widened his perspectives and brought him into close contact with contemporary British ethnologists such as Tylor, Frazer and Lang adopting their theoretical principles (survivals, historical-comparative method, Kyriakidou-Nestoros 1978: 103-105). All in all, Politis was a contradictory yet also an exciting personality. His studies and his theoretical interventions in general influenced the arts and the politics of his time. However, what mostly characterized his work was his anxiety over the future of the Greek national state. For him folk studies were established in order to support the national state; that is why he called them 'national' studies. Replying to a member of Laographia, the journal of Greek Association of Folklore (1909), he makes the following comment: "The nation needs to recognize its authentic national constituents, to be conscious of its national character and to extinguish those extrinsic elements that distort that character. This could happen by studying the Greek people's life and the expressions of their own psyche" (Politis 1909: 156).

Politis's approach was not novel during his time. Rather, he belonged to an international group of folklorists formulating similar arguments in order to enhance ethnocentrism and homogenization processes (Oinas 1978; Öztürkmen 1993). That was exactly Politis's target. In his view, the Greek psyche is out of time, eternal. It comes unchangeably from the past up to the present. Thus, examining thoroughly the cultural products of contemporary Greece would enable the folklorists of the time to collect material for the trilateral historical scheme that connected ancient, Byzantine and modern times.

However, this ethnocentric approach lead to an extreme stance concerning the concept of 'otherness', whether internal or external. In the case of the internal 'Other', as folk studies concentrated only on similarities, they side- 
stepped the differences between various Greek localities, regarding them as dangerous vis-à-vis the argument of the eternal psyche. Homogenization and the stressing of similarities constituted the only path that led to the Greek psyche and to the ultimate origin as well. As concerns the external 'Other', located outside the Greek borders, one can discern an extremely xenophobic attitude; a good example of how the relevant attitude got inscribed in contemporary folk studies is Politis's treatise on Bulgarian bandit songs (kleftika tragoudia) where he argued that the research of the relevant songs enables folklorists to observe the superiority of the Greek culture against the Bulgarian one. Greek songs, in his view, were more refined than the Bulgarian ones which depicted a less evolved culture. Naturally, we have to underline that such an argument can be understood only if examined in view of the Balkan history. It was the period of implacable fights among Balkan peoples to widen their national territory. Consequently, such ethnocentric and xenophobic approaches belonged to the ideological arsenal of Balkan ethnicities trying to promote their own interests while the Ottoman Empire collapsed.

However, the shifting from theory (questions over identity) to practice (military action and political intervention at an international level) lasted until the interwar period, when the Great Idea lost its weight within the Greek national ideology and when the Greek army was defeated by Ataturk's troops in Asia Minor. That was a turning point for Greece. The Great Idea had no longer any influence on politics, on science and on society in general. Continuity as a concept had lost its energy.

Moreover, the new social environment that had been emerging after the settlement of 1,500,000 Greek refugees from Asia Minor transformed the overall attitude towards otherness. Before the catastrophe in Asia Minor, the 'Other' was initially the Ottoman Empire and later those Balkan nations which demanded territories that the Greeks regarded as their own to be integrated or retained in their own state. However, things changed and the concept of the 'Other' acquired a new meaning. A debate was launched over the content of Greekness, a term which replaced 'Hellenism'. The Nobel laureate, Giorgos Seferis, and his own generation of poets proposed a new orientation. They suggested that Greece should open up to international relations. Their idea of Greekness entailed closer links with Western Europe, an idea which encountered fierce opposition. The debate over the essence of Greekness, which prevailed at the time, was absolutely crucial, since its outcome was to have a tremendous impact on the social and political life of the Greek nation.

Moreover, one more representation of the 'Other' emerged. It was Marxism and the Greek Communist Party, the foundation of which was regarded as a serious danger for the homogenizing process within the Greek nation. Stilpon 
Kyriakidis, the second professor of folklore in Greece, at the newly founded Aristotle University of Thessaloniki (1923), regarded communism as the greatest danger and based his argument on how wrong Marx's and Engels's ideas were concerning the origin of the family. Kyriakidis sensed that those ideas could undermine the Greek family, which was considered to be a cohesive social bond and a creator of culture.

At the end of the 1940's when the Balkan states changed their political system, coming under the control of the Soviet Union, a new borderline was drawn in Europe. As a consequence, the concepts and definitions of folk studies in Greece took on new differentiated meanings.

\section{STILPON KYRIAKIDIS AND THE INTERWAR PERIOD: COMMUNISM AS OTHERNESS}

Politis passed away in 1921. Kyriakidis was elected professor two years later. The period of two years, however, was enough for the political climate to be subverted. The catastrophe in Asia Minor took place in 1922. Thousands of Greeks who had lived for centuries in that area were forced by Turkish troops to abandon Asia Minor. As mentioned above 1,500,000 refugees settled in Greece. This was an adequate reason for changing the orientation of folk studies.

For Kyriakidis folk studies were still a national science. However, they now took on a new meaning. They no longer aimed at providing national authorities with the necessary arguments concerning the origin of the Greek - regarding the population outside the national boundaries. Now, folk studies were mainly focusing on substantiating the Greekness of those northern areas of the country which stretched along the borderline with the neighbouring Balkan states. In the final analysis, I would argue that the so-called communist threat had the same effects as the Great Idea. For, in the same way as the latter had energized Politis and also the Greek authorities, the former, which was labelled 'the northern danger', energized Kyriakidis. Indeed, most of his research was devoted to historical issues concerning the Greekness of the population of Northern Greece, that is of Macedonia and Thrace.

However, the existence of the so-called communist threat did not only affect the folk studies of the time but also the very politics of the Greek nation. Bulgaria, for example, was one of the newly established national states of the 19th century, which, for Greeks, constituted a threat along its northern boundaries. In the 1940's Bulgaria became part of the Communist camp in Eastern Europe. Although this appears to have been a great shift, in reality, it was not. 
At the bottom of the 'Bulgarian threat' was the same old problem, that is, the question of homogeneity in the Greek nation, a problem which, at the time, imbued all the spheres of the public life of the country.

Kyriakidis insisted on the national character of folk studies but he interpreted its content differently. The catastrophe of Asia Minor had deprived him of the concept of the Great Idea which was a cornerstone for the folk studies of the time. Thus, he had to re-orient his research choices. In his effort to prove how untenable was Marx's and Engels's theory about the origin of the family he found recourse to Malinowski's functionalism, which enabled him to get round the concept of evolutionism. Kyriakidis sensed that continuity based on survivals and evolutionism was a very slippery path. So he utilized the theory of cultural circles. Functionalism, moreover, armed him with the epistemological tools in order to fight communism. A holistic approach was a convenient methodological prospect for him in order to dodge the Marxist theory of class struggle, which divided society into separate sectors.

Kyriakidis differentiated himself from Politis first of all by criticizing the latter for having given an archaeological dimension to folk studies by characterizing survivals as the main methodological tool and secondly, by reproving Politis's insistence on amateur collectors (students, teachers) of folk material. Himself, he resorted to functionalism in order to borrow its holistic approach. He believed that this methodological principle could help him prevent communist ideas from undermining the cohesion of the Greek nation. Moreover, he was convinced that the holistic approach was an appropriate tool since it allowed him to study folk culture as a unity; that was a point which clearly differentiated him from Politis who defined folk studies as a science studying dimensions of social and cultural life, following the principles of historicalcomparative method.

Although Kyriakidis adopted a holistic definition, his stance was contradictory: on the one hand he showed the population of a nation as 'homogeneous', and on the other, he divided culture into two parts: that of the superior classes and that of the lower classes. He was trapped in his fears. As a result he had no systematic relationship with the theory and the methodology of functionalism. What he did was to amass functional fragments which provided him with arguments. In that sense one might argue that he was not in a reality a functionalist but he only borrowed some of the ideas of functionalism. In fact, Kyriakidis never abandoned the historical methodology. Despite his criticism of Politis's insistence on the concept of 'survival' and of his promoting an archaeological dimension in the studying of folk culture, Kyriakidis himself gradually slid into an acceptance of the concept of continuity. 


\section{POST-WORLD WAR II PERIOD}

\section{Georgios Megas: ethnocentrism, civil war, and systematic research}

Ethnocentrism as well as the character of a 'national discipline' kept on being a recognizable context for the folk studies of the post World War II period. Georgios Megas, the third most important Greek folklorist was elected professor of folklore at the University of Athens in 1947, the year when the Greek civil war broke out. Given the political atmosphere of the time, it was only natural that folk studies would cling to the dogma of ethnocentrism. Megas's inaugural lecture, for instance, not only expressed his disagreement with the political upset but also his support for the right wing camp which clearly used ethnocentric arguments.

Megas agreed with Kyriakidis in identifying the 'Other' with the so-called 'communist threat'. He took it for granted that the national character of folk studies was still valid, although the content of the latter was now different, despite their similarities with Kyriakidis's views. Megas was convinced that, under the circumstances, the national target should be the 'discovery' of the folk psyche, as this would highlight the deepest common elements that united all Greeks and would, consequently, assuage the divisive forces of the time.

Thus, he chose to focus mainly on folk tales and on folk housing; that would be the path that would lead him to the folk psyche. His research gradually acquired autonomy as time went by and Megas became well known as an international expert in folktales, while his articles on folk housing in the Greek countryside are unique. Moreover, folk housing facilitated him to formulate a premature ecological approach during the first post war decades, by extending his research object to the natural, social and cultural environment.

Megas resorted to Riehl's volksgeist in order to avoid the brutal present (the civil war, the exiles and later on the cold war) and in order to discover the deepest cohesive substratum in folk culture. That was the essence of volksgeist. He was the first Greek folklorist who was at the same time a fieldworker, visiting many areas and spending time there. He was interested in collecting material for implementing his plans. However, his fieldwork reoriented his research directions. He observed that building solutions in folk housing did not only depend on the historical cultural capital. Craftsmen were not just passive bearers of a national tradition. They possessed a familiarity with the materials (stone, wood) and with the local cultural capital (social institutions, economy and mentalities) allowing them to cope with construction problems. It is obvious that the relevant researches by Megas deviated both from the concept of continuity and from a historical method. On the one hand he kept 
on defining folk studies as a 'national science'. On the other hand, even in his folktale studies, he was at a distance from the idea of continuity. He eventually joined the Finnish school which was not exclusively interested in tracking down the ancient Greek origin of folklore material. Instead, he tried to establish contemporary Greek ecotypes of world-wide folktales.

\section{Dimitrios Loukatos: French-educated and looking at the changing society}

All three folklorists, discussed so far, were educated in Germany, which explains why their orientation was rather one-sided. The first Greek folklorist who was not educated in Germany was Dimitrios Loukatos who was the chair of the Greek Folklore Association in the early 2000's. He was educated in France and this was indeed visible in the way he perceived folk studies. He introduced the concept of change in his perspective, which had been very weak in Megas's scientific thought. Loukatos did not look backwards. On the contrary, he was interested in dealing with progress. To understand Loukatos's perspective we have to take into consideration the new intellectual ambience in Greece during the first two decades after the war. The Greek countryside lost its population which migrated mainly to Athens and to other big cities (Thessaloniki, Patras, Ioannina). Moreover, the sharp increase in the urban population generated a thriving building industry, as well as a consequent transformation in attitudes, in behavior, in habits and customs. Greece entered a phase leading to major structural changes, which meant that nothing could now be approached in the ways of Politis, Kyriakidis or Megas.

Loukatos, being familiar with sociological and ethnological bibliography, noticed the changes in contemporary Greek society and introduced the concept of change into his folkloristic perspective; consequently, he defined the concept of 'people' differently and thus widened the boundaries of folk studies. For him 'people' lived everywhere; they were not limited to the countryside. That is why he accepted urban space as a field for folk studies: on the one hand a large number of domestic migrants lived there, retaining or modifying their own cultural behaviour, and on the other, new cultural phenomena emerged (folklorism, plastic products, ordinary life, open-air markets, etc.).

Loukatos rejected the national character of folk studies; he did not see them as responsible for reinforcing national cohesion by proposing each time a representation of 'otherness'. Rather, he re-signified the term 'national discipline': he suggests that the main target of folk studies should be national consciousness, which drives people to self-control. In that way they become capable of fighting off their own faults while enhancing those virtues which come to 
empower national consciousness. Moreover, Loukatos argues that national consciousness is the only safe way towards the maintenance of national distinctness.

Loukatos believed that the national target should be related to well-being and spiritual welfare. Thus, folk studies, for him, should help people defend themselves against the cultural and social crises that Greek society had been undergoing since the Second World War. That was why he rid folk studies of the ideological burden of the past and allocated to them the role of bridging the past with the present and of reinforcing the self-confidence of the Greek people, which had been traumatized by the German occupation and the civil war.

However, Loukatos was not given the opportunity to implement his vision: because he refused to co-operate with the military dictatorship of the 1960's, which had invoked communist dangers to subvert a democratic government, he was made to resign from his position at the University of Ioannina. So he became the only folklorist who had officially disagreed with the state ideology. Some of the younger folklorists widened Loukatos's perspective intensifying, in that way, changes in folk studies. That happened for the first time after the restoration of democracy in 1974. Then two very promising young folklorists appeared on the scene: Professor Michalis Meraklis at the University of Ioannina and Professor Alki Kyriakidou-Nestoros, Kyriakidis's daughter, at the Aristotle University of Thessaloniki.

\section{The generation of the 1970's and new perspectives on folklore studies: Michalis G. Meraklis and Alki Kyriakidou-Nestoros}

Both of them contributed to the modernization of folk studies in Greece. Meraklis, educated in Germany, was influenced by Bausinger's radical ideas. He regarded 'folklorism' as a new field for folk studies. So he dealt with urban phenomena introducing a sociological dimension in his approaches. He also researched the phenomenon of tourism in relation to the environment and the new mentalities. What, however, was Meraklis's greatest contribution to scientific thought was the revision of classifying criteria in folk studies and he himself regarded collectivity as the only criterion.

Furthermore, Meraklis defined the notion 'national discipline' in geographical terms, i.e. he explained that folk studies are the science which focuses on the culture of people living within the national boundaries. He rejected any nationalistic use of the term. However, his definition was valid before the reorientation of the field of the science of anthropology. The next generation of folklorists ceased invoking the national character of folk studies. Anthropology entered Greece and the majority of anthropologists shared the same field as the folklorists. 
Kyriakidou-Nestoros was the first folklorist to introduce an anthropological perspective into folk studies. She was a disciple of Lévi-Strauss. She never regarded folk studies as a national science. Instead, she believed that folk studies could lead to the deepest understanding of human culture. Although she initially oscillated between being a folklorist and an anthropologist, she eventually decided to be a folklorist. Her major contribution was the inoculation of folk studies with the theory of social anthropology and oral history.

The 1980's was a very crucial decade for folk studies in Greece since two university departments of anthropology were founded for the first time: as a result anthropology was introduced in Greece and folk studies lost their exclusive hegemony over cultural studies.

\section{FOLKLORE STUDIES AND SOCIAL ANTHROPOLOGY IN GREECE: THE POLARIZING STEREOTYPES}

Soon, however, things became polarized between folklorists and anthropologists: there were hurt feelings, stereotyping, refusal, on both parts, of collaboration and participation in the same conferences. Both groups demanded the same space, the same staff positions. Let me refer to my own experience. My department, founded in 1998, became the theatre of such an antagonism between folk studies and social anthropology. The official title of the unit was the Department of History, Archaeology and Folklore. Some years later, however, the newly elected board of directors decided to change the third part of its designation by replacing 'folklore' with 'social anthropology'. Since then all the staff positions have been defined by the phrase 'anthropology of...'.

Let me remind readers at this point that Greece became a full member of the European Union in 1981, that is, four years before the foundation of the first departments of anthropology. Thus, the conflict between folk studies and anthropology mirrored a complicated situation concerning the kind of national identity the Greeks looked for as well as the position they would like to have as a nation in the European Union. A significant percentage of Greeks opposed the idea of the European Union and saw the perspective of the country's complete integration as a threat for the national economy and culture. They demonized the European Union as well as the prospect of globalization; their view was, and to some extent still is, that they would generate homogenization which would threaten Greek cultural distinctness.

In the above ideological ambience, folk studies were identified with those who were sceptical about the European Union. Anthropologists grasped the opportunity to blame folklorists for expressing political conservatism and iso- 
lationism as well as ethnocentrism, at a time when anthropology, representing cosmopolitanism and modernization, was introducing new ideas into Greece. Eventually, anthropologists ended by questioning the very scientific discipline of folk studies.

Now, on their part, folklorists defended themselves by accusing anthropologists for having no relationship whatsoever with Greek culture, for being arrogant and for exhibiting scholarly 'aestheticism'. Furthermore, folklorists identified anthropology with ideological colonialism as well with globalization, and some of them went as far as to imply that anthropology could be serving the political interests of foreign powers. Eventually, folklorists saw themselves as heroes who stood up against whatever anthropology expressed.

Twenty years later things have changed. Folk studies in Greece have by now widened their spectrum. The above-mentioned stereotypes no longer respond to what is happening now, at the beginning of the 21 st century. There is still a group of folklorists who prefer the traditional road by collecting and describing material. However, the number of folklorists with different ideas is increasing. Most of them have chosen to introduce anthropological theory into their own perspective, which has weakened the borderline between anthropology and folk studies.

\section{THE FUTURE}

To sum up, I think that folk studies could continue their scholarly route in the future if they accepted the necessity for changes in both theory and method. Nowadays the political and ideological ambience has changed. Even in the case of political frictions with F.Y.R.O. Macedonia nobody asks the Greeks to document their descent from ancient Greece. Thus folk studies are obliged to transform their identity precisely because Greece is now different, the whole world is different. I would say that the route of folk studies in Greece is one-way. The discipline has to intensify its communication with theory. Such an opening up of Greek folk studies would be greatly profited, in my view, by the infusion of theory and interdisciplinary dialogue. 


\section{REFERENCES}

Darko, Kristo 1917.The Albanians. Ylli I Mengjezit, Vol. 1, No. 3, pp. 67-73.

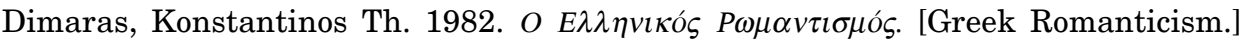
Athens: Hermes Editions.

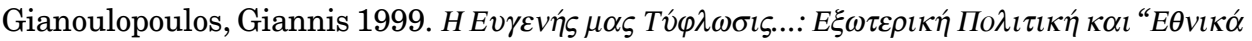

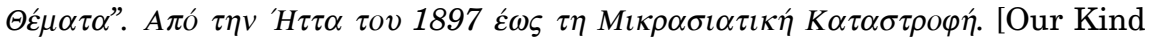
Blindness... Foreign Policy and National Issues. From the Defeat of 1897 to the Minor Asia Catastrophe.] Athens: Vivliorama.

Fallmerayer, Jakob Philipp 1830. Geschicte der Halbinsel Morea Während des Mittelalters, Vol.1. Stuttgart und Tübingen.

Herzfeld, Michael 1986. Ours Once More: Folklore, Ideology and the Making of Modern Greece. New York: Pella Publishing Company.

Herzfeld, Michael 1987. Anthropology through the Looking-Glass: Critical Ethnography in the Margins of Europe. Cambridge: Cambridge University Press.

Jusdanis, Gregory 2001. The Necessary Nation. Princeton, New Jersey: Princeton University Press.

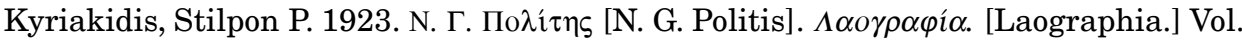
$\mathrm{Z}^{\prime}$, pp. $\theta^{\prime}-\kappa \varsigma^{\prime}(7-26)$.

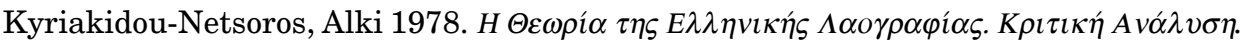
[The Theory of Greek Folklore. Critical Analysis.] Athens: Society for Neohellenic Cultural and Educational Studies.

Mazower, Mark 2002. The Balkans: A Short History. New York: Modern Library Chronicles.

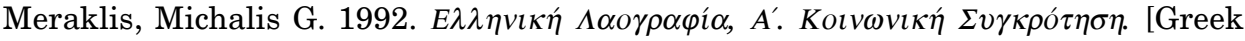
Folklore, A. Social Formation.] Athens: Odysseas.

Nisbet, H. B. 1999. Herder. The Nation in History. In: M. Branch (ed.) National History and Identity. Approaches to the Writing of National History in the North-East Baltic Region Nineteenth and Twentieth Centuries. Studia Fennica Ethnologica 6. Helsinki: Finnish Literature Society, pp. 78-96.

Oinas, Felix J. (ed.) 1978. Folklore, Nationalism and Politics. Columbus, Ohio: Slavica Publishers

Öztürkmen, Arzu 1993. Folklore and Nationalism in Turkey. A Dissertation in Folklore and Folklife presented to the faculties of the University of Pennsylvania in partial fulfillment of the requirements for the degree of Doctor of Philosophy.

Papageorgiou, Stefanos P. 2004. A

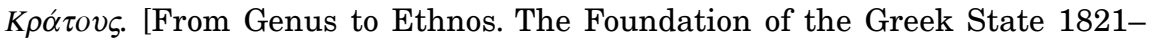
1862.] Athens: Papazisis Publications.

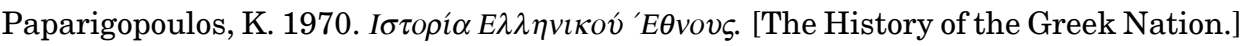
Athens: Hermes Editions.

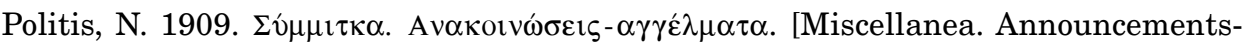
Tidings.] $\Lambda \alpha о \gamma \rho \alpha \varphi i ́ \alpha$. [Laographia.] Vol. A', pp. 156-157.

Roudometof, Victor 2001. Nationalism, Globalization, and Orthodoxy: the Social Origins of Ethnic Conflict in the Balkans. Westport: Greenwood Press. 


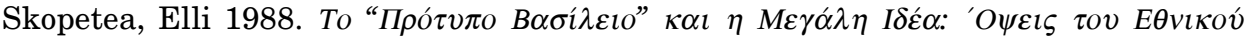

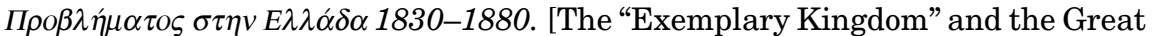
Idea: Aspects of the National Question in Greece 1830-1880.] Athens: Ekdoseis Polytypo.

Shafer, Boyd 1972. Faces of Nationalism: New Realities and Old Myths. New York: Harcourt Brace Jovanovich.

Shannan Peckham, Robert 2004. Internal Colonialism. Nation and Region in Nineteenth-Century Greece. In: M. Todorova (ed.) Balkan Identities. Nation and Memory. New York: New York University Press, pp. 41-59.

Smith, Anthony D. 1986. The Ethnic Origins of Nations. Oxford: Basil Blackwell.

Todorova, Maria N. 1997. Imagining the Balkans. New York: Oxford University Press.

Wilson, William A. 1976. Folklore and Nationalism in Modern Finland. Bloomington: Indiana University Press.

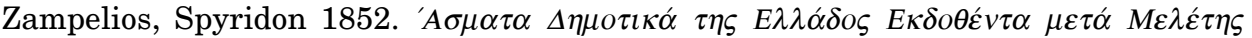

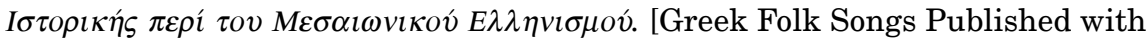
a Historical Study on Mediaeval Hellenism.] Athens: Typographeion Hermes. 